\title{
Glottal Marking of Vowel-Initial Words in German
}

\author{
Bernd Pompino-Marschall
}

Institut für deutsche Sprache und Linguistik der Humboldt-Universität zu Berlin Zentrum für Allgemeine Sprachwissenschaft, Berlin

Marzena Żygis

Zentrum für Allgemeine Sprachwissenschaft, Berlin

Glottal marking of vowel-initial German words by glottalization and glottal stop insertion were investigated in dependence on speech rate, word type (content vs. function words), word accent, phrasal position and the following vowel. The analysed material consisted of speeches of Konrad Adenauer, Thomas Mann and Richard von Weizsäcker. The investigation shows that not only the left boundary of accented syllables (including phrasal stress boundary) and lexical words favour glottal stops/glottalization, but also that the segmental level appears to have a strong impact on these insertion processes. Specifically, the results show that low vowels in contrast to non-low ones favour glottal stops/glottalization even before non-accented syllables and functional words.

\section{Introduction}

Glottal stops and glottalization have attracted increasing interest from phonologists and phoneticians, probably due to their hardly definable, almost chameleon-like behavior.

Several phonetically oriented studies have reported huge variability of glottal stops and glottalizations in their acoustic realization. Moreover, their presence or absence - unless they have a phonemic status in a given language is also subject to variation despite well-defined rules (see the results of the present study). This inter- and intra-speaker variability has been observed in a number of languages and shown to be dependent on several parameters such as: phrasal position, accented vs. unaccented syllable, segmental context, speech rate, dialect, speaker's gender, and others. (see e.g. American English: Umeda 1978, Pierrehumbert 1994, Pierrehumbert \& Talkin 1991; Redi \& ShattuckHufnagel 2001; Chitwan Tharu: Leal 1972, Danish: Haberland 1994; Garo: 
Burling 1992, Nootka: Shank \& Wilson 2000; Tümpisa (Panamint) Shoshone: Dayley 1989).

From a phonological point of view the discussion often focuses on phonological alternations, (e.g. /h/- vs. [?]-alternation in Pima Bajo, Fernández 1996), grammatical functions of glottal stop insertions (e.g. glottal stop as a marker of the irrealis mood, i.e. future, imperative, and purposive verb forms in Nhanda Blevins \& Marmion 1995), the appearance of glottal stops at prosodic constituent boundaries, (e.g. glottal stop appearance in utterance-initial position in Anejom Lynch 2000) or phonotactic restrictions, (e.g. in Nootka glottalized elements are banned from the coda Shank \& Wilson 2000).

As far as German, the language of the main interest for the present study, is concerned it has not been extensively investigated as far as glottalizations and glottal stops are concerned. Phonetically, the topic was investigated by e.g. Krech (1968), Kohler (1994), Rodgers (1999) (see section 0). Phonologically, it has been stated that glottal stops are found as onsets of vowel-initial stressed syllables. Hall (1992) shows that the glottal stop occurs optionally at the beginning of a vowel-initial foot, cf. examples in (1). The same view is shared by Wiese (2000).

(1) Glottal Stop Insertion in German (Hall 1992:58).

arm [?aRm $]$ or [aRm] 'poor'

oft [?oft] or [oft] 'often'

Theater [te.Pá:.te] or [te.á:.te] 'theater'

An analysis presented by Alber (2001) refers to morphological boundaries and shows that a glottal stop appears in Standard German in two contexts: (i) at the left edge of a vowel-initial stressed syllable and (ii) at the left edge of a vowelinitial root or prefix. Alber (2001:6) concludes 'that stress can favor the presence of glottal closure, though it is less clear whether the difference between stressed and unstressed syllables is strong enough to be integrated into a phonological analysis.'

The aim of this paper is to investigate the appearance of glottal stops (and glottalization) in German spontaneous speech by looking what extent this appearance depends on other parameters such as speech rate, prosodic boundary, phrasal position, accented vs. unaccented segmental context, content vs. function words, and how large the inter- and intraspeaker variation is with respect to the presence/absence of glottal stops and glottalizations.

The paper is organized as follows. In section 2 we provide a brief overview of studies on glottal stops and glottalization focusing on three selected papers. Section 3 introduces the experimental design of the present study and section 4 
provides results. Main conclusions of the paper are summarized and discussed in section 5 .

\section{Glottal stops and glottalizations: Previous studies}

As mentioned in the previous section, glottal stops and glottalization have sparked much interest in phonetics and phonology. In this section we focus on three papers, namely Umeda (1978), Kohler (1994) and Redi \& ShattuckHufnagel (2001) which in our view are of particular importance for the present study.

\subsection{Umeda (1978)}

The use of glottal stops in continuous speech in American English has been the subject of Umeda's (1978) study. In this study, five speakers read sentences excerpted from four short stories (each story contained about 30 sentences). The sentences were randomized and read in form of a list. In the second part of the experiment the informants read the stories in their original form. The data were analyzed with respect to the occurrence of glottal stops in dependence of several factors such as speaker's reading style, difficulty of the material, phonemes following the glottal stops, stress conditions, type of words (function vs. content words), and frequency of occurrence of words. In general, the results lead to the conclusion that the speaker's reading style and difficulty of material influence the insertions of glottal stops stronger than phonological and grammatical factors. The study emphasizes great inter-speaker variation related to individual reading styles (the staccato type of speaking shows more glottal stops than fluent speaking). Slow speech rate also induces a higher percentage of glottal stops than high speech rate (the slowest speaker showed the largest number of glottal stops, i.e. about $80 \%$ of the total occurrence of vowel-initial content words with the first syllable stressed, and the fastest speaker the least, i.e. about $25 \%$ ). It was also shown that grammatical breaks between phrases of the same kind as e.g. listings of nominal phrases, breaks after adverbs however, instead, or clause boundaries induce a high percentage of glottal stop insertions even before function words.

The study furthermore shows that rare words are more frequently marked with glottal stops than common words. No significant differences in glottal stop assignment have been found regarding the effect of tongue height in vowels and the presence/absence of the pitch contour on vowels. 


\subsection{Kohler (1994)}

Kohler's (1994) paper focuses on glottal stops and glottalization occurring in German colloquial read speech of a North German non-dialect variety. On the basis of an auditory and acoustic study of speech data from 36 speakers of the PhONDAT 90/93 Kiel database (IPdS 1994, 1995ff.), Kohler reports on the occurrence of glottal stops and glottalization as morphological boundary markers including word-internal boundaries on the one hand and as reduction phenomena of supraglottal stop articulations on the other hand.

The results show that glottalization is the most frequent realization of the canonical glottal stop in German. After pauses/silence, the presence of a glottal stop is substantially more frequent than its absence. Stressed vowels favour the presence of glottal stops/glottalization substantially more than unstressed ones in a continuous segmental context. The highest proportion of glottal stops is found before stressed vowels and after plosives $(72 \%)$. The preceding plosive context also triggers the highest proportion of glottal stops before unstressed vowels (35 \% as opposed to $17 \%-20 \%$ in other contexts, i.e., preceding vowels, sonorants, and fricatives.) As far as word-internal boundaries are concerned it has been found that between prefix and stem as well as between components of compounds simple glottalization is the most frequent pattern (62\%) followed by glottal stop and glottalization (24\%) and glottal stop deletions (10\%). The least frequent realisation was a single glottal stop (4\%). Finally, Kohler (1994) shows that glottal stops and glottalization replace (i) stops $/ \mathrm{t} /$ and $/ \mathrm{k} /$ at the word boundary, e.g. Freita[k] abend 'Friday evening' is realized as Freita[?] abend and (ii) syllable-final plosives, especially before and/or after a nasal, e.g. hi[ntən] is pronounced as hi[n?n] 'behind'. The former case has been found in 4 instances and the latter in 48 (Kohler 1994: 45).

\subsection{Redi \& Shattuck-Hufnagel (2001)}

This study reports on glottalization in American English observed in different contexts, for instance in word-initial vowels at intonation phrase onsets and at pitch accents as well as at the ends of utterances. The study also investigates glottalized voice quality occurring as an allophone of voiceless stops (in e.g. butler). Speech material was obtained from two corpora of spoken utterances: Labnews consisted of read speech produced by six professional radio news announcers. A part of the materials was also produced by four nonprofessional speakers. The second corpus, called the ABC corpus, contained read speech produced by four nonprofessional speakers of $\mathrm{AE}$.

The acoustic analysis shows that glottalization is realized as (i) aperiodicity (irregular periods), (ii) creak (lowering of fundamental frequency with near-total 
damping), (iii) diplophonia (alternation in shape, amplitude, or duration of successive periods) and (iv) glottal squeak (occurring adjacent to other types of glottalization, and perceived as a momentary shift to a relatively high-pitched and low amplitude voice quality). The results show a great range in the rate of glottalization in individual speakers' pronunciations. It appears that this rate is higher on words at the ends of utterances than on words at the ends of utterancemedial intonational phrases. Finally, it is shown that the rate of glottalization is higher at the boundaries of full intonational phrases than at intermediate intonational phrases.

\section{Present study: Method}

The glottal marking of vowel-initial words were analysed in historical recordings of prominent Germans (Konrad Adenauer, Thomas Mann, Richard von Weizsäcker) taken from the CD collection "Tondokumente zur deutschen Geschichte" (Audio documents of German history; Stiftung deutsches Rundfunkarchiv 2004ff.). Three recordings of each speaker were extracted from the audio CDs to *.wav files using CDex, leaving the sample rate at $44.1 \mathrm{kHz}$ and segmented/annotated in PRAAT. Statistical analyses were conducted with the help of the STATVIEW software.

Our three selected speakers were Konrad Adenauer (1876-1967; first Federal German chancellor 1949-1963); Thomas Mann (1875-1955, famous writer and Nobel prize winner 1929) and Richard von Weizsäcker $(* 1920$, Federal German president 1984-1994). The acoustic analysis included three speeches of each speaker:

(i) Adenauer: 1929, 1949a, b,

(ii) Mann: 1945, 1949, 1950,

(iii) von Weizsäcker 1984, 1989, 1992.

The analyzed material summed up to 29.04 minutes of recording time, cf. details presented in Table 1.

\subsection{Procedure}

The recordings were first transcribed orthographically and segmented with respect to pauses $(>150 \mathrm{~ms})$. Information on the duration of pause delimited utterances, the number of syllables produced and the duration of the following pause were stored in tabular form for the later analysis of speech rate. The orthographic transcript was then scanned for vowel initial words. ${ }^{1}$

1 Word-internal boundaries as after prefixes (e.g. vereisen [fe?aIzən]) and in compounds (e.g. Feierabend [fare?a:bənt]) are excluded from the current analysis. 
In a second annotation/segmentation step these word-initial vowels were classified as being unmarked, marked by glottalization (creaky voice) or by a glottal stop proper. Marked items were segmented with respect to the beginning and end of single pitch periods, i.e. glottalizations from the first to the last irregular pitch period (onset of modal voicing), glottal stops from burst/first affected pitch period to the onset of modal voicing (segmentation of the closed phase was difficult or impossible (i.e. utterance-initially). Figure 1 illustrates segmentation in examples from Mann (1950).

(a)

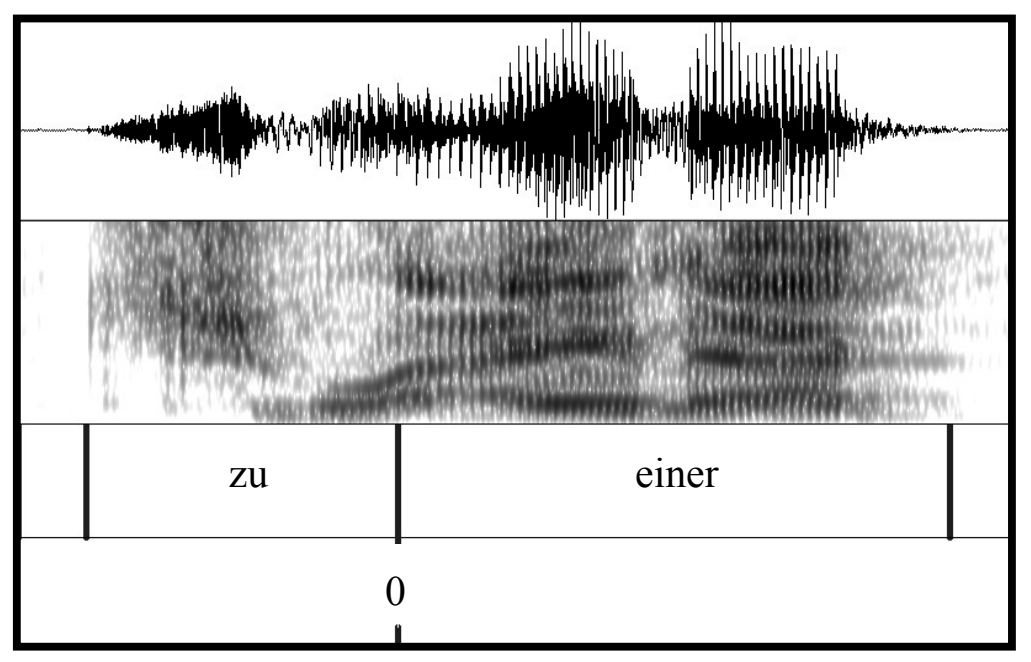

(b)

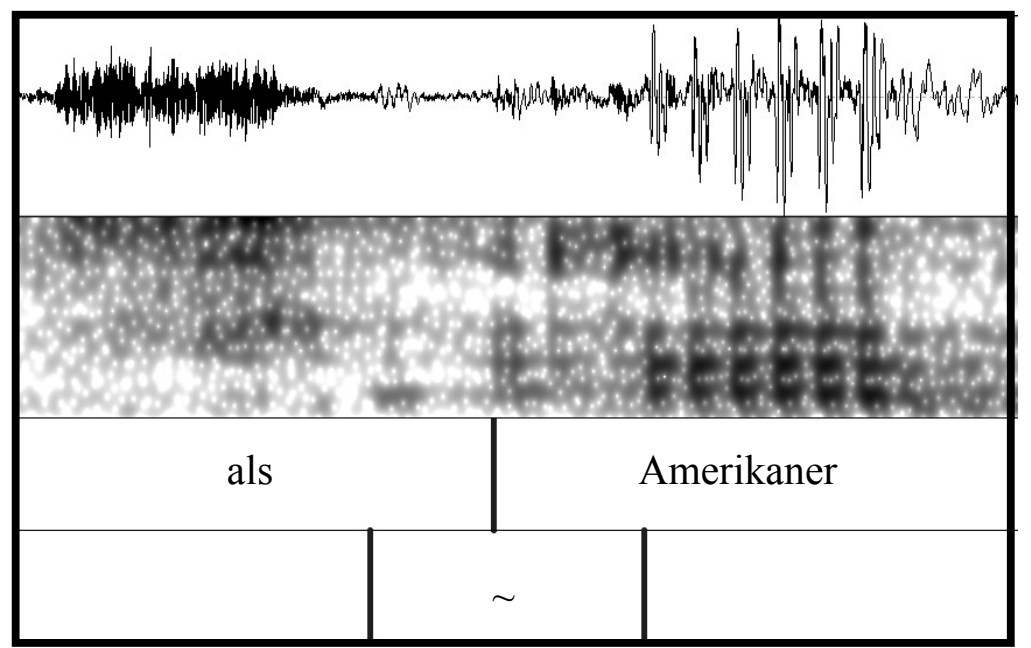


(c)

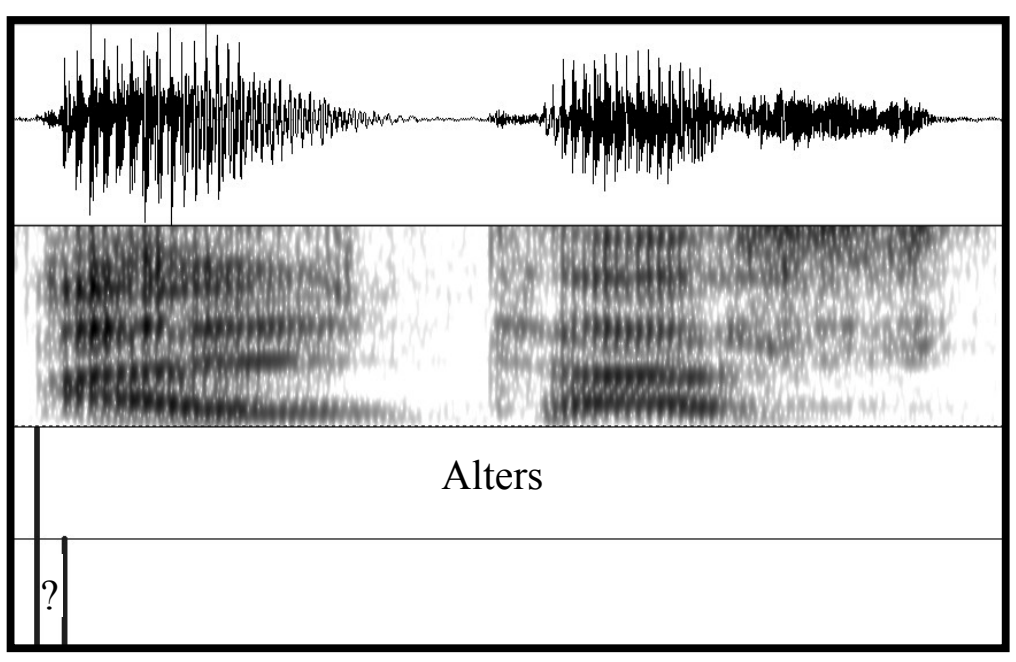

Figure 1: Sample segmentations of wordinitial vowel markings in the material of Mann (1950): (a) unmarked, (b) marked by glottalization $(61 \mathrm{~ms})$, (c) marked by glottal stop (18 ms).

\section{$4 \quad$ Results}

In a first step the segmented material was analyzed with respect to its general temporal makeup as described in 4.1. In 4.2 we will then present the results with respect to glottal markings in vowel-initial words.

\subsection{General}

Table 1 gives an overview of the results with respect to recording durations ${ }^{2}$ and speakers' recording durations (with and without intervening pauses), single utterance length, syllable counts, pause durations and speech rate (articulatory rate, i.e. syllables/utterance duration [s]) depending on speaker and recording. Table 1 also includes the statistical results of ANOVAs and post hoc Scheffe tests with speaker and take as independent variables, and utterance length, syllable count, pause duration or articulatory rate as dependent variables; $*$ : $\mathrm{p}<$ $.05 ; * *: \mathrm{p}<.01 ; * * *: \mathrm{p}<.001)$.

2 Values differing from those given on the resource $\mathrm{CD}$ are due to initial and final silent parts in the original material and/or material excluded in the present analysis (e.g. reporter's voice in Adenauer 1949a). 
The utterance durations are generally longest for Richard von Weizsäcker, significantly differing from those of Konrad Adenauer as well as Thomas Mann. This may be due to their nature as highly prepared Christmas broadcasts in TV. Whereas Richard von Weizsäcker as well as Thomas Mann show the same utterance durations in all their speeches, Konrad Adenauer's utterance durations are significantly longer in his governmental address (Adenauer 1949b), again possibly due to the nature of this highly prepared text. These results are paralleled by significantly larger syllable counts together with a marginal difference between two recordings of Thomas Mann. Pause durations show up more variable between and within speakers, Thomas Mann here showing the smallest values throughout. Speech rate turned out to be quite speaker-specific, with clear significant differences between the fastest speaker (Richard von Weizsäcker) and the others as well as between the following two, i.e. Konrad Adenauer and Thomas Mann. Only Thomas Mann exhibits a slower speech rate once, i.e. in his post-war BBC broadcast. This could possibly be due to technical reasons. For the more detailed analysis of glottal markings given below, we therefore decided to base speech rate dependent analysis on the quartile ranges (also given in Table 1 and depicted in Figure 2) for the three speakers separately. 
Table 1: Statistical data of the analysed material in a general overview

\begin{tabular}{|c|c|c|c|c|c|c|c|c|c|}
\hline speaker & \multicolumn{3}{|c|}{ Konrad Adenauer } & \multicolumn{3}{|c|}{ Thomas Mann } & \multicolumn{3}{|c|}{ Richard von Weizsäcker } \\
\hline date & 1929 & $1949 a$ & $1949 b$ & 1945 & 1849 & 1950 & 1984 & 1989 & 1992 \\
\hline $\begin{array}{l}\text { recording } \\
\text { duration } \\
\text { [min's"] }\end{array}$ & 2'15" & 2'40" & 3'58" & 2'17"' & 6'43" & 4'34" & 2'55" & 1'44" & 2'38" \\
\hline $\begin{array}{l}\text { speaker } \\
\text { sum }\end{array}$ & \multicolumn{3}{|c|}{ 8'53" } & \multicolumn{3}{|c|}{ 13'34" } & \multicolumn{3}{|c|}{ 7'17" } \\
\hline $\begin{array}{l}\text { speaking } \\
\text { duration } \\
\text { [min's"] }\end{array}$ & 1'30" & 4'44" & 2'44" & 1'47" & 4'44" & 3'16 & 2'07" & 1'13" & 1'46" \\
\hline $\begin{array}{l}\text { speaker } \\
\text { sum }\end{array}$ & \multicolumn{3}{|c|}{ 6'00" } & \multicolumn{3}{|c|}{ 9'47" } & \multicolumn{3}{|c|}{ 5'06" } \\
\hline $\begin{array}{l}\text { utterance } \\
\text { duration } \\
\text { mean (sd) } \\
\text { [s] }\end{array}$ & $\begin{array}{c}* \star * \\
1.50 \\
(.848)\end{array}$ & $\begin{array}{c}1.77 \\
(.937) \\
* *\end{array}$ & $\begin{array}{c}-* * * \\
2.34 \\
(1.236) \\
\longrightarrow * *\end{array}$ & $\begin{array}{c}1.99 \\
(1.068)\end{array}$ & $\begin{array}{c}1.79 \\
(1.022)\end{array}$ & $\begin{array}{c}1.899 \\
(1.109)\end{array}$ & $\begin{array}{c}2.58 \\
(1.256)\end{array}$ & $\begin{array}{c}2.10 \\
(1.267)\end{array}$ & $\begin{array}{c}2.13 \\
(.929)\end{array}$ \\
\hline $\begin{array}{l}\text { speaker } \\
\text { mean (sd) } \\
{[\mathrm{s}], \mathrm{N}}\end{array}$ & \multicolumn{3}{|c|}{$\begin{array}{c}{ }^{\star *} \bullet \\
1.90 \\
(1.088) \\
239\end{array}$} & \multicolumn{3}{|c|}{$\begin{array}{c}1.86 \\
(1.058) \\
458 \\
\star \star\end{array}$} & \multicolumn{3}{|c|}{$\begin{array}{c}-* * \\
2.29 \\
(1.161) \\
258 \\
-* *\end{array}$} \\
\hline $\begin{array}{l}\text { syllables } \\
\text { per } \\
\text { utterance } \\
\text { mean (sd) } \\
\text { range }\end{array}$ & $\begin{array}{c}* * \star \\
5.67 \\
(3.261) \\
1-15\end{array}$ & $\begin{array}{c}6.92 \\
(4.077) \\
2-18 \\
* \star\end{array}$ & $\begin{array}{c}-* * * \\
9.04 \\
(5.057) \\
1-21 \\
\bullet^{* *}\end{array}$ & $\begin{array}{c}* \bullet-- \\
8.11 \\
(4.653) \\
2-20\end{array}$ & $\begin{array}{c}\bullet * \\
6.35 \\
(4.445) \\
1-26\end{array}$ & $\begin{array}{c}6.43 \\
(3.841) \\
1-18\end{array}$ & $\begin{array}{c}12.61 \\
(6.757) \\
3-31\end{array}$ & $\begin{array}{c}10.34 \\
(6.668) \\
2-33\end{array}$ & $\begin{array}{c}11.18 \\
(5.263) \\
1-29\end{array}$ \\
\hline $\begin{array}{l}\text { speaker } \\
\text { mean (sd) } \\
\text { range }\end{array}$ & \multicolumn{3}{|c|}{$\begin{array}{c}\star \star \bullet \\
7.31 \\
(4.457) \\
1-21\end{array}$} & \multicolumn{3}{|c|}{$\begin{array}{c}6.68 \\
(4.331) \\
1-26 \\
* \star\end{array}$} & \multicolumn{3}{|c|}{$\begin{array}{c}-* * \\
11.49 \\
(6.237) \\
1-33 \\
-* *\end{array}$} \\
\hline $\begin{array}{l}\text { pause } \\
\text { duration } \\
\text { mean (sd) } \\
{[\mathrm{ms}]}\end{array}$ & $\begin{array}{c}* \bullet \\
754 \\
(501.0)\end{array}$ & $\begin{array}{c}903 \\
(486.0)\end{array}$ & $\begin{array}{l}\bullet * \\
1064 \\
(971.2)\end{array}$ & $\begin{array}{c}* \bullet- \\
552 \\
(286.6) \\
*\end{array}$ & $\begin{array}{c}\longrightarrow * \\
752 \\
(524.7)\end{array}$ & \begin{tabular}{c}
765 \\
$(492.7)$ \\
\hdashline$*$
\end{tabular} & $\begin{array}{c}1014 \\
(576.6)\end{array}$ & $\begin{array}{c}878 \\
(761.3)\end{array}$ & $\begin{array}{c}1035 \\
(693.7)\end{array}$ \\
\hline $\begin{array}{l}\text { speaker } \\
\text { mean } \\
(\mathrm{sd})\end{array}$ & \multicolumn{3}{|c|}{$\begin{array}{c}* \star \bullet \\
916 \\
(718.2)\end{array}$} & \multicolumn{3}{|c|}{$\begin{array}{c}\bullet * \star \\
722 \\
(486.2) \\
* * \star\end{array}$} & \multicolumn{3}{|c|}{$\begin{array}{c}986 \\
(671.3) \\
-\bullet^{\star \star \star}\end{array}$} \\
\hline $\begin{array}{l}\text { speech } \\
\text { rate } \\
\text { mean (sd) } \\
{[\text { syll./s] }}\end{array}$ & $\begin{array}{c}3.79 \\
(.817)\end{array}$ & $\begin{array}{c}3.86 \\
(.886)\end{array}$ & $\begin{array}{c}3.81 \\
(.804)\end{array}$ & $\begin{array}{c}* \star * \\
4.05 \\
(.742) \\
* \star \star\end{array}$ & $\begin{array}{c}-\bullet * \star * \\
3.49 \\
(.906)\end{array}$ & $\begin{array}{c}3.45 \\
(.902) \\
-\bullet \star \star \star\end{array}$ & $\begin{array}{c}4.83 \\
(.657)\end{array}$ & $\begin{array}{c}4.80 \\
(.841)\end{array}$ & $\begin{array}{c}5.16 \\
(.983)\end{array}$ \\
\hline $\begin{array}{l}\text { speaker } \\
\text { mean } \\
\text { (sd) }\end{array}$ & \multicolumn{3}{|c|}{$\begin{array}{c}* \star \\
3.82 \\
(.831) \\
* \star \star\end{array}$} & \multicolumn{3}{|c|}{$\begin{array}{c}* * / * \star * \\
3.57 \\
(.904)\end{array}$} & \multicolumn{3}{|c|}{$\begin{array}{c}\star \star \star \\
4.95 \\
(.849) \\
* \star \star \star\end{array}$} \\
\hline $\begin{array}{l}\text { speech } \\
\text { rate } \\
\text { quartiles } \\
\text { [syll./s] }\end{array}$ & $\begin{array}{l}3.305 \\
3.890 \\
4.179\end{array}$ & $\begin{array}{l}2.837 \\
3.729 \\
4.334\end{array}$ & $\begin{array}{l}3.192 \\
3.844 \\
4.376\end{array}$ & $\begin{array}{l}3.544 \\
4.101 \\
4.598\end{array}$ & $\begin{array}{l}2.795 \\
3.431 \\
4.131\end{array}$ & $\begin{array}{l}2.786 \\
3.347 \\
3.946\end{array}$ & $\begin{array}{l}4.378 \\
5.000 \\
5.207\end{array}$ & $\begin{array}{l}4.305 \\
4.925 \\
5.260\end{array}$ & $\begin{array}{l}4.525 \\
5.166 \\
5.756\end{array}$ \\
\hline $\begin{array}{l}\text { speaker } \\
\text { mean } \\
\text { quartiles }\end{array}$ & \multicolumn{3}{|c|}{$\begin{array}{l}3.305 \\
3.831 \\
4.317\end{array}$} & \multicolumn{3}{|c|}{$\begin{array}{l}2.889 \\
3.522 \\
4.131\end{array}$} & \multicolumn{3}{|c|}{$\begin{array}{l}4.410 \\
5.010 \\
5.394\end{array}$} \\
\hline
\end{tabular}




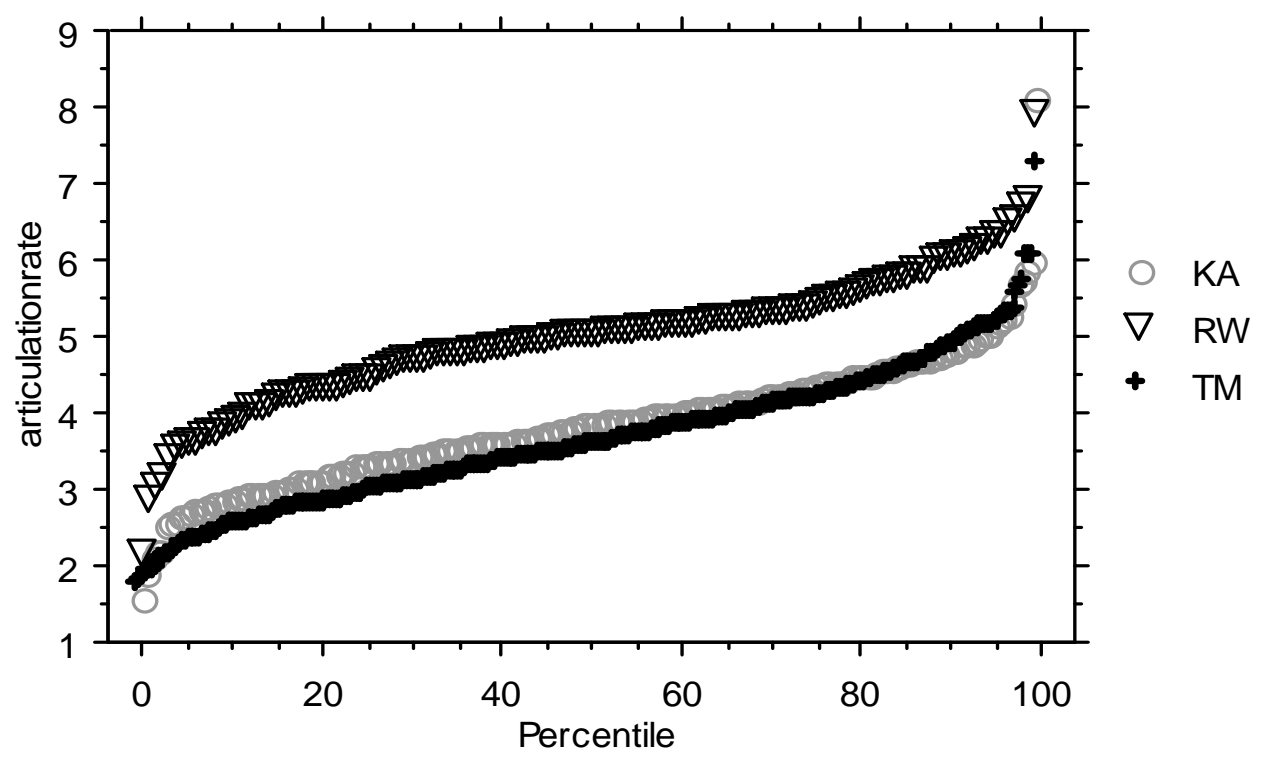

Figure 2: Percentile plot of the distribution of speech rates per utterance split by speakers

\subsection{Marking of word-initial vowels}

The distribution frequencies of the differently marked vowel-initial words were analyzed with respect to the speaker specific speech rates. So the nonmarked, glottalized and abrupt vowel onsets (i.e. those with preceding glottal stop) were counted separately in slow (i.e. first quartile of the speakers' rate range, cf. Figure 2), slow medium (second quartile), fast medium (third quartile) and fast rate (fourth quartile) utterances. The following tables always show the relative frequencies of marking type for each single condition (Table 2: speaker/tempo; Table 3: word type/tempo; Table 4: stress/tempo; Table 5: phrasal position/tempo; Table 6: vowel height/tempo) since absolute counts were not under control due to the experimental design. Note that further splitting up was not feasible since the number of occurences for different tokens would have become too small.

Table 2 depicts the speech rate dependent distribution of glottal markings in vowel-initial words for our three speakers (separately and in general). As can be seen, the glottal marking of word-initial vowels is generally diminishing with increasing speech rate: nonmarked items continuously rise in frequency from about $30 \%$ in slow speech ( $1{ }^{\text {st }}$ quartile of the speakers' rate ranges) to more than $50 \%$ in fast speech; on the other hand, realisations of canonical glottal stop 
stepwise reduce from $48 \%$ in slow speech to ca. $16 \%$ in fast speech, parallel to an increase in markings by creaky voice only (from about $22 \%$ to about $31 \%$ ).

Besides this general trend there are some interesting differences between the speakers: For Adenauer we can see a change from glottal stop marking at slower rates to a loss of marking in faster speech. For Weizsäcker, who is from a younger generation, marking by glottalization seems to be preferred at almost all rates (with the exception of equally frequent markings by glottal stop at the slowest and some more losses of marking at the fastest rate). Thomas Mann's behaviour, lying in between both these extremes, more closely resembles that of Adenauer in this respect.

Table 2: Rate-dependent relative frequencies of glottal markings of word-initial vowels (0: unmarked, : creaky voice, ?: glottal stop; speaker-dependent and overall; most frequent marking per rate (and speaker) highlighted in bold (with equal frequencies also in italics))

\begin{tabular}{|c|c|c|c|c|c|c|c|c|c|}
\hline marking & speaker & \multicolumn{2}{|c|}{ slow } & \multicolumn{2}{|c|}{ slow medium } & \multicolumn{2}{|c|}{ fast medium } & \multicolumn{2}{|c|}{ fast } \\
\hline \multirow{3}{*}{0} & KA & 40.0 & \multirow{3}{*}{30.1} & 37.5 & \multirow{3}{*}{38.9} & 50.0 & \multirow{3}{*}{40.0} & 64.6 & \multirow{3}{*}{53.} \\
\hline & TM & 24.1 & & 45.8 & & 43.2 & & 53.9 & \\
\hline & RW & 29.4 & & 28.8 & & 26.0 & & 44.4 & \\
\hline \multirow{3}{*}{$\sim$} & $\mathrm{KA}$ & 08.6 & \multirow{3}{*}{22.0} & 15.6 & \multirow{3}{*}{23.4} & 11.5 & \multirow{3}{*}{30.7} & 22.9 & \multirow{3}{*}{30.6} \\
\hline & TM & 22.2 & & 13.3 & & 24.2 & & 26.1 & \\
\hline & RW & 35.3 & & 44.2 & & 55.2 & & 43.1 & \\
\hline \multirow{3}{*}{$?$} & KA & 51.4 & \multirow{3}{*}{48.0} & 46.9 & \multirow{3}{*}{37.7} & 38.5 & \multirow{3}{*}{29.3} & 12.5 & \multirow{3}{*}{16.2} \\
\hline & TM & 53.7 & & 41.0 & & 32.6 & & 20.0 & \\
\hline & RW & 35.3 & & 26.9 & & 17.9 & & 12.5 & \\
\hline
\end{tabular}

In Table 3 the relative frequency of different markings is given with respect to word type (content words vs. function words). The fact of diminishing glottal marking with increasing speech rate mentioned above clearly shows up to be dependent on word type: Content words are more resistant to the total loss of marking at higher rates in contrast to the generally unstressed function words.

Table 3: Rate-dependent relative frequencies of glottal markings in content words (c) vs. function words (f) (0: unmarked, : creaky voice, ?: glottal stop; most frequent marking per rate and word type in bold)

\begin{tabular}{|c|c|c|l|l|l|l|l|l|}
\hline & \multicolumn{2}{|c|}{ slow } & \multicolumn{2}{c|}{ slow medium } & \multicolumn{2}{c|}{ fast medium } & \multicolumn{2}{c|}{ fast } \\
\hline & $\mathrm{C}$ & $\mathrm{f}$ & $\mathrm{C}$ & $\mathrm{f}$ & $\mathrm{C}$ & $\mathrm{f}$ & $\mathrm{C}$ & $\mathrm{f}$ \\
\hline 0 & 15.4 & 36.9 & 23.6 & $\mathbf{4 6 . 9}$ & 22.4 & $\mathbf{5 1 . 1}$ & 25.7 & $\mathbf{6 6 . 1}$ \\
\hline$\sim$ & 20.5 & 22.6 & 32.7 & 18.9 & $\mathbf{4 2 . 1}$ & 23.7 & $\mathbf{5 4 . 3}$ & 19.1 \\
\hline$?$ & $\mathbf{6 4 . 1}$ & $\mathbf{4 0 . 5}$ & $\mathbf{4 3 . 7}$ & 34.2 & 35.5 & 25.2 & 20.0 & 14.8 \\
\hline
\end{tabular}


Therefore, in Table 4 the effect of stress on the relative frequency of glottal markings in vowel-initial content words is shown. Due to the smaller number of tokens the results are not as clearcut as before, but the general tendency of unstressed items to lose markings at lower rates than stressed ones is still visible.

Table 4: Rate-dependent relative frequencies of glottal markings in stressed vs. unstressed content words (f) (0: unmarked, : creaky voice, ?: glottal stop; most frequent marking per rate and word type in bold (with equal frequencies also in italics))

\begin{tabular}{|c|l|l|l|l|l|l|l|l|}
\hline & \multicolumn{2}{|c|}{ slow } & \multicolumn{2}{c|}{ slow medium } & \multicolumn{2}{c|}{ fast medium } & \multicolumn{2}{c|}{ fast } \\
\hline & +stressed & -stressed & +stressed & -stressed & +stressed & -stressed & +stressed & -stressed \\
\hline 0 & 10.7 & 27.3 & 11.4 & $\mathbf{4 2 . 1}$ & 21.8 & 25.0 & 12.5 & $\mathbf{5 4 . 6}$ \\
\hline$\sim$ & 14.3 & $\mathbf{3 6 . 3 5}$ & 42.9 & 15.8 & 43.6 & 40.0 & $\mathbf{6 8 . 7 5}$ & 22.7 \\
\hline$?$ & $\mathbf{7 5 . 0}$ & $\mathbf{3 6 . 3 5}$ & $\mathbf{4 5 . 7}$ & $\mathbf{4 2 . 1}$ & 34.5 & 35.0 & 18.75 & 22.7 \\
\hline
\end{tabular}

The effect of phrasal position on the nature of glottal marking, shown in Table 5, also shows a tendency of stronger marking in phrase initial items but this effect seems rather weak, i.e. only visible at slow medium rate, cf. Rodgers (1999).

Table 5: Rate-dependent relative frequencies of glottal markings in phrase-initial words vs. non phrase-initial words (f) (0: unmarked, : creaky voice, ?: glottal stop; most frequent marking per rate and position in bold)

\begin{tabular}{|c|l|l|l|l|l|l|l|l|}
\hline & \multicolumn{2}{|c|}{ slow } & \multicolumn{2}{c|}{ slow medium } & \multicolumn{2}{c|}{ fast medium } & \multicolumn{2}{c|}{ fast } \\
\hline & \multicolumn{1}{|c|}{ initial } & non-initial & \multicolumn{1}{c|}{ initial } & non-initial & initial & non-initial & initial & non-initial \\
\hline 0 & 33.3 & 29.3 & 28.2 & $\mathbf{4 2 . 2}$ & $\mathbf{5 0 . 0}$ & $\mathbf{3 7 . 2}$ & $\mathbf{5 9 . 2}$ & $\mathbf{5 1 . 6}$ \\
\hline$\sim$ & 12.5 & 24.2 & 00.0 & 30.5 & 11.9 & 35.5 & 06.1 & 37.1 \\
\hline$?$ & $\mathbf{5 4 . 2}$ & $\mathbf{4 6 . 5}$ & $\mathbf{7 1 . 8}$ & 27.3 & 38.1 & 27.3 & 34.7 & 11.3 \\
\hline
\end{tabular}

So far we may conclude in parallel to the published results that the marking of vowel-initial words in German is realized (a) in a rate-dependent manner ranging from glottal stop insertion via glottalisation to no marking at all. The strength of marking is influenced by the intervening variables of (b) word type, (c) stress and (d) phrasal position: content words are more strongly marked than function words, stressed initial vowels more strongly than unstressed ones. Position within the phrase affected the speech rate dependent realization of glottal marking only at slow medium rate of articulation.

In contrast to Umeda (1978), who found no differences of glottal marking with respect to vowel identity in American English, our German material clearly shows a dependency of marking on vowel height (cf. Table 6). 
Table 6: Vowel-height and rate-dependent relative frequencies of glottal markings of wordinitial vowels (0: unmarked, : creaky voice, ?: glottal stop; most frequent marking per rate and vowel height highlighted in bold (with equal frequencies also in italics))

\begin{tabular}{|l|l|l|l|l|l|l|l|l|l|l|l|l|l|}
\hline & \multicolumn{4}{|c|}{ slow } & \multicolumn{3}{c|}{ slow medium } & \multicolumn{3}{c|}{ fast medium } & \multicolumn{3}{c|}{ fast } \\
\hline & low & mid & high & low & mid & high & low & mid & high & low & mid & high \\
\hline 0 & 07.7 & 25.0 & $\mathbf{4 5 . 3}$ & 13.5 & $\mathbf{3 5 . 3}$ & $\mathbf{5 5 . 3}$ & 18.6 & $\mathbf{4 7 . 2}$ & $\mathbf{5 7 . 0}$ & 25.6 & $\mathbf{5 6 . 8}$ & $\mathbf{7 0 . 0}$ \\
\hline$\sim$ & 15.4 & $\mathbf{4 0 . 0}$ & 20.3 & 28.8 & 29.4 & 17.5 & 39.5 & 30.6 & 22.6 & $\mathbf{4 7 . 4}$ & 32.4 & 19.2 \\
\hline$?$ & $\mathbf{7 6 . 9}$ & 35.0 & 34.4 & $\mathbf{5 7 . 7}$ & $\mathbf{3 5 . 3}$ & 26.3 & $\mathbf{4 1 . 9}$ & 22.2 & 20.4 & 26.9 & 10.8 & 10.8 \\
\hline
\end{tabular}

We could therefore add to our observations that (e) low vowels are more strongly marked by glottal stops and glottalization than non-low ones, cf. Krech (1968).

In addition to the rate-dependent distributional analysis of glottal markings, we finally analyzed the durational characteristics of glottal markings. The results of this analysis are given in Table 7 below.

An ANOVA of the duration of glottal marking (with marking type, rate and speaker as independent variables) revealed the expected ${ }^{3}$ highly significant $(\mathrm{p}<$ .001) difference between glottalizations and glottal stops and a tendency for an interaction between marking type and rate with a significant $(p<.05)$ but not systematic effect of rate for glottalizations (cf. Table 7).

Table 7: Rate-dependent durational characteristics of glottal markings (mean (sd) in ms, [N]; $\sim$ : creaky voice, ?: glottal stop)

\begin{tabular}{|c|c|c|c|c|}
\hline glottal marking & slow & $\begin{array}{c}\text { slow } \\
\text { medium }\end{array}$ & $\begin{array}{c}\text { fast } \\
\text { medium }\end{array}$ & fast \\
\hline & 68 & 88 & 93 & 73 \\
& $(26)$ & $(36)$ & $(62)$ & $(29)$ \\
& {$[27]$} & {$[39]$} & {$[85]$} & {$[72]$} \\
\hline \multirow{2}{*}{21} & 20 & 20 & 19 \\
& $(14)$ & $(9)$ & $(9)$ & $(11)$ \\
& {$[58]$} & {$[63]$} & {$[62]$} & {$[38]$} \\
\hline
\end{tabular}

\footnotetext{
${ }^{3}$ Due to our segmentation strategy.
} 


\section{Summary and discussion}

Glottal marking of vowel-initial words in spontaneous German speech again was shown to be remarkably variable. From a phonetic point of view it is best described as realizations along a continuous scale of vocal fold adduction/compression giving rise to exactly timed canonical glottal stop insertions before onset vowels at the extreme value of glottal activation changing to amalgams of glottal stop and glottalization as well as less strictly timed glottalization at word boundaries (cf. Figure 3) to only minor reflexes in fundamental frequency and no reflexes at all in the stream of voicing. ${ }^{4}$

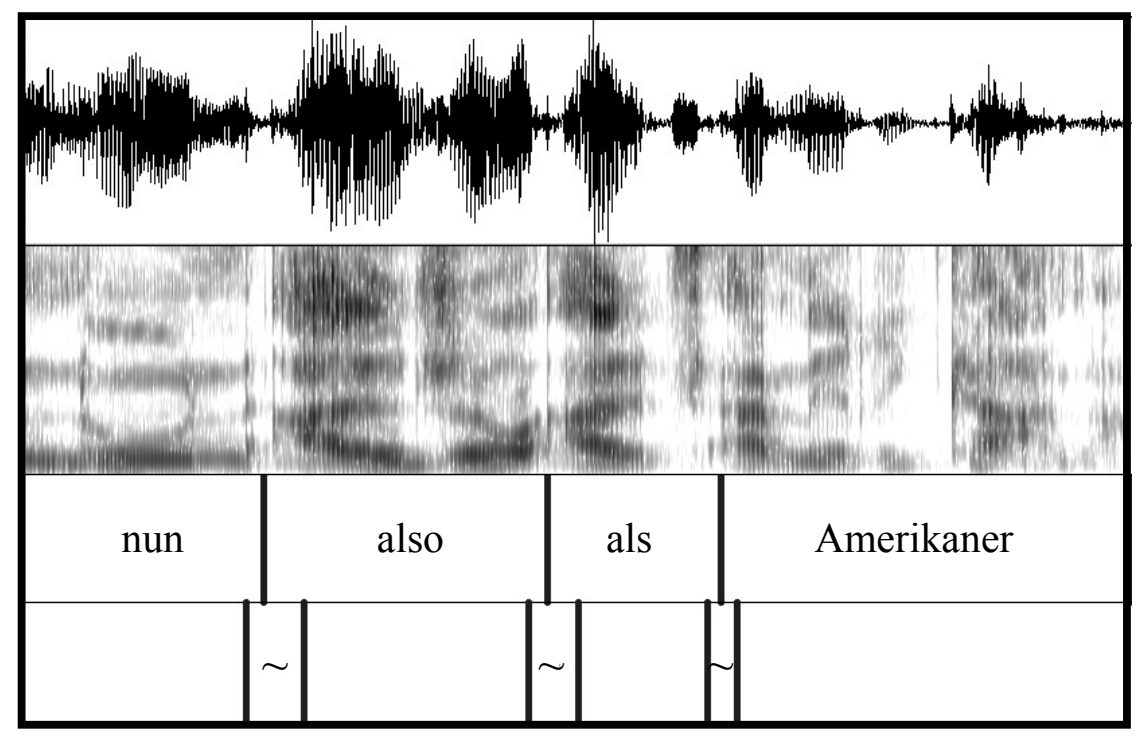

Figure 3: Three examples of glottalizations in sequence spanning the word boundary in Mann (1950)

In any annotation scheme this glottal behavior will result in a more categorical scale. As our results show, the distribution of the different marking categories (i.e. [?], [ ] and 0) is highly dependent on a number of factors. But, in general, it is clearly dependent on speech rate, irrespective of all other factors under consideration. This again speaks for its principally gradual nature. Parallel to the published results presented in section 2 we found that linguistic variables like word type, word accent and (to a lesser degree) phrasal position all influence the relative frequency of glottal markings in a rate-dependent way. This shows the importance or even superiority of speech rate over other parameters. On the other hand it could be shown that glottal marking is also dependent on the very

4 In strictly post-pausal position, this continuum is paralleled by hard, glottalized and smooth onset of the initial vowel. 
nature (i.e. tongue height) of the marked vowel itself, cf. also Krech (1968). This finding has an important implication for prosodic research, namely, it shows that glottal stops/glottalizations are not only conditioned by prosodic boundaries but depend on segmental level as well. It remains to be answered by future research why glottal stops occur more frequently before low vowels and how this cooccurrence is to be understood in terms of the interplay of segmental and prosodic levels of representations.

Finally, the present study provides important material for phonological approaches to German prosody showing that the present accounts of glottalization and glottal stops need to be extended by taking into consideration the complexity of phonetic evidence.

\section{References}

Alber, Birgit (2001). Regional variation and edges: Glottal stop epenthesis and dissimilation in standard and southern varieties of German. Zeitschrift für Sprachwissenschaft 20, 341.

Adenauer, Konrad (1929). Grundsteinlegung zum Neubau der Universität Köln (26.10.1929). In: Stiftung deutsches Rundfunkarchiv (2005). Tondokumente zur deutschen Geschichte. Konrad Adenauer. 5. Januar 1876 - 19. April. 1967 Braunschweig: Archiv Verlag, Track 1.

Adenauer, Konrad (1949a). Feststellung der Annahme des Grundgesetzes durch Konrad Adenauer (23.05.1949). In: Stiftung deutsches Rundfunkarchiv (2005). Tondokumente zur deutschen Geschichte. Gründung der beiden deutschen Staaten. Braunschweig: Archiv Verlag, Track 3.

Adenauer, Konrad (1949b). Regierungserklärung des Bundeskanzlers Konrad Adenauer (20.09.1949). In: Stiftung deutsches Rundfunkarchiv (2005). Tondokumente zur deutschen Geschichte. Gründung der beiden deutschen Staaten. Braunschweig: Archiv Verlag, Track 5.

Blevins, Juliette \& Doug Marmion (1995). Nhanda glottal stop. Oceanic Linguistics 34. 139160.

Burling, Robbins (1992). Garo is a minimal tone language. Linguistics of the Tibeto-Burman Area 15.5, 33-51.

Dayley, Jon P. (1989). Tümpisa (Panamint) Shoshone Grammar. University of California. Publications in Linguistics vol. 115. University of California Press.

Fernández, Zarina Estrada (1996): Prima Bajo. München: Lincom.

Haberland, Hartmut (1994) Danish. In: König, Ekkehard \& Johan van der Auwera (eds.). The Germanic Languages. London: Routledge, 313-348.

Hall, Tracy Alan (1992). Syllable Structure and Syllable-Related Processes in German. Tübingen: Max Niemeyer Verlag. 
IPdS (1994), The Kiel Corpus of Read Speech. Vol. I [Kiel-CD \#1]. Institut für Phonetik und digitale Sprachverarbeitung der Christian-Albrechts-Universität zu Kiel.

IPdS (1995ff.), The Kiel Corpus of Sontaneous Speech. Vol. I [Kiel-CD \#2 (1995)], Vol. II [Kiel-CD \#3 (1996)], Vol. III [Kiel-CD \#4 (1997)]. Institut für Phonetik und digitale Sprachverarbeitung der Christian-Albrechts-Universität zu Kiel.

Kohler, Klaus J. (1994). Glottal stops and glottalization in German. Data and theory of connected speech processes. Phonetica 51, 38-51.

Krech, Eva-Maria (1968). Sprechwissenschaftlich-phonetische Untersuchungen zum Gebrauch des Glottalschlageinsatzes in der allgemeinen deutschen Hochlautung. Basel: Karger.

Leal, Dorothy (1972). Chitwan Tharu Phonemic Summary. Kirtipur: Summer Institute of Linguistics and Institute of Nepal Studies, Tribhuvan University.

Lynch, John (2000). A Grammar of Anejom. [Pacific Linguistics 507]. Canberra: The Australian National University.

Mann, Thomas (1945). “Deutsche Hörer!” - Rundfunkansprache über den deutschsprachigen Dienst der BBC (24.05.1945). In: Stiftung deutsches Rundfunkarchiv (2006). Tondokumente zur deutschen Geschichte. Neubeginn nach dem Zusammenbruch 1945 bis 1949. Braunschweig: Archiv Verlag, Track 1.

Mann, Thomas (1949). Ansprache zum Goethe-Jahr in der Frankforter Paulskirche (25.07.1949). In: Stiftung deutsches Rundfunkarchiv (2007). Tondokumente zur deutschen Geschichte. Emigration und Rückkehr in die fremd gewordene Heimat. Braunschweig: Archiv Verlag, Track 5.

Mann, Thomas (1950). Vortrag "Meine Zeit" anlässlich seines 75. Geburtstags (21.05.50). In: Stiftung deutsches Rundfunkarchiv (2008). Tondokumente zur deutschen Geschichte. Große Reden - die Macht des Wortes. Braunschweig: Archiv Verlag, Track 3.

Pierrehumbert, Janet (1994). Prosodic effects on glottal allophones. In: Fujimura, O. \& M. Hirano (eds). Vocal Fold Physiology 8: Voice Quality Control. San Diego: Singular Press, 39-60.

Pierrehumbert, Janet \& David Talkin, (1991). Lenition of $/ \mathrm{h} /$ and glottal stop. Papers in Laboratory Phonology II. Cambridge UK: Cambridge Univ. Press, 90-117.

Redi, Laura \& Stefanie Shattuck-Hufnagel (2001). Variation in the realization of glottalization in normal speakers. Journal of Phonetics 29, 407-429.

Rodgers, Jonathan (1999). Three influences on glottalization in read and spontaneous German speech. Arbeitsberichte des Instituts für Phonetik und digitale Sprachverarbeitung der Universität Kiel (AIPUK) 34, 173-280

Shank, Scott \& Ian Wilson (2000). An acoustic analysis of vowel formants in pharyngeal and glottal contexts in Nuu-chah-nulth. University of Washington Working Papers in Linguistics 19, 75-84.

Stiftung deutsches Rundfunkarchiv (2004ff.). Tondokumente zur deutschen Geschichte. Braunschweig: Archiv Verlag [continuously enlarged series of audio CDs]. 
Umeda, Noriko (1978). Occurrence of glottal stops in fluent speech. JASA 64, 81-94.

Weizsäcker, Richard von (1984). Weihnachtsansprache (24.12.1984). In: Stiftung deutsches Rundfunkarchiv (2007). Tondokumente zur deutschen Geschichte. Die Bundespräsidenten - Weihnachts- und Silvesteransprachen. Braunschweig: Archiv Verlag, Track 11.

Weizsäcker, Richard von (1989). Weihnachtsansprache (24.12.1989). In: Stiftung deutsches Rundfunkarchiv (2007). Tondokumente zur deutschen Geschichte. Die Bundespräsidenten - Weihnachts- und Silvesteransprachen. Braunschweig: Archiv Verlag, Track 12.

Weizsäcker, R. von (1992). Weihnachtsansprache (24.12.1992). In: Stiftung deutsches Rundfunkarchiv (2007). Tondokumente zur deutschen Geschichte. Die Bundespräsidenten - Weihnachts- und Silvesteransprachen. Braunschweig: Archiv Verlag, Track 13.

Wiese, Richard (2000). The Phonology of German. Oxford: Oxford University Pres 